Original Article

\title{
DETERMINATION OF 2-CYANO-4'-BROMOMETHYL BIPHENYL GENOTOXIC IMPURITY IN IRBESARTAN DRUG SUBSTANCES USING HPLC TECHNIQUE
}

\author{
S. SENTHIL KUMAR ${ }^{a^{*},}$ RITESH KUMAR SRIVASTAVA ${ }^{\mathrm{b}}, \mathrm{V}$. SRINIVAS RAO ${ }^{\mathrm{a}}$ \\ aFaculty of Pharmacy, Pacific Academy of Higher Education and Research University, Udaipur 313004, Rajasthan, India, bAnalytical \\ Research and Development, Macleods Pharmaceuticals Limited, R and D Center, Mumbai 400059, India
}

Email: chensenk@gmail.com

Received: 12 Aug 2016 Revised and Accepted: 18 Oct 2016

\section{ABSTRACT}

Objective: The objective of present study was to develop and validate a specific and sensitive HPLC method for the quantitative determination of genotoxic impurity 2-cyano-4'-bromomethyl biphenyl present in irbesartan drug substance.

Methods: The development activity was conducted by HPLC with UV as a detector. The impurity was separated on Kromasil C18 $250 \mathrm{x} 4.6 \mathrm{~mm}, 5 \mu \mathrm{m}$ analytical column with a mobile phase consisting of buffer $\mathrm{pH} 3.2$ and acetonitrile in the ratio of $60: 40 \mathrm{v} / \mathrm{v}$ at a flow rate $1.5 \mathrm{ml} / \mathrm{min}$. The effluent was monitored by UV detection at $258 \mathrm{~nm}$ with column temperature maintained at $40{ }^{\circ} \mathrm{C}$ and the injection volume $30 \mu \mathrm{l}$. Acetonitrile was selected as diluent.

Results: Validation activity was planned and completed based on the ICH guideline. The LOD and LOQ value were found to be $0.167 \mu \mathrm{g} / \mathrm{g}$ and $0.506 \mu \mathrm{g} / \mathrm{g}$ and accuracy results were well in the range 98.34 to $103.46 \%$. The linearity curve showed the correlation coefficient of 0.9999 and method very sensitive.

Conclusion: From validation data, it was confirmed that the developed method is specific, sensitive, linear, precise and accurate for the determination of 2-cyano-4'-bromomethyl biphenyl genotoxic impurity in irbesartan drug substances.

Keywords: Impurity, HPLC, TTC, Validation, ICH guidelines

(C) 2016 The Authors. Published by Innovare Academic Sciences Pvt Ltd. This is an open access article under the CC BY license (http://creativecommons.org/licenses/by/4. 0/) DOI: http://dx.doi.org/10.22159/ijpps.2016v8i12.14682

\section{INTRODUCTION}

Irbesartan is a non-peptide tetrazole derivative drug, chemically described as 2-butyl-3-(\{4-[2-(2H-1,2,3,4-tetrazol-5-yl)phenyl] phenyl\} methyl)-1,3diazaspiro [4.4] non-1-en-4-one [1]. Its molecular formula is $\mathrm{C}_{25} \mathrm{H}_{28} \mathrm{~N}_{6} \mathrm{O}$ and molecular weight 428.53 [2]. The drug is used mainly for the treatment hypertension and commercially available in $75 \mathrm{mg}, 150 \mathrm{mg}$ and $300 \mathrm{mg}$ of tablet strength either individually or combination with other antihypertensive drugs [3-5].

2-cyano-4'-bromomethyl biphenyl is the most important intermediate used in the synthesis of irbesartan [6, 7]. This is identified as a genotoxic impurity in irbesartan according to the guidelines [8,9]. Based on the threshold of toxicological concern (TTC) and the maximum daily dosage of irbesartan the evaluation limit of its genotoxic impurity is calculated $5.00 \mu \mathrm{g} / \mathrm{g} \mathrm{[8].} \mathrm{The}$ chemical structures of irbesartan and 2-cyano-4'-bromomethyl biphenyl are presented in fig. $1[6,7]$.

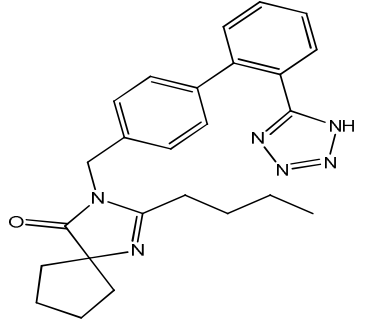

(a)

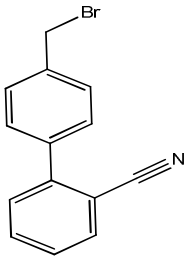

Fig. 1: Chemical structure of (a) Irbesartan and (b) 2-cyano-4'bromomethyl biphenyl

Detailed literature survey reveals that the many HPLC methods are available for the determination of the drugs individually or in combination with other drugs [10-13]. However, very few analytical methods are available for the determination of genotoxic impurity in irbesartan drug by LC-MS/MS [14] and UPLC [15] technique. There was no HPLC method available for quantitative determination of 2cyano-4'-bromomethyl biphenyl in irbesartan.

Because of literature gap for the determination of 2-cyano-4'bromomethyl biphenyl genotoxic impurity, we have reported here in a specific and sensitive HPLC analytical method, which separates the impurity from the drug substances and also could quantify the impurity at less than $50 \%$ to the evaluation limit.

\section{MATERIALS AND METHODS}

\section{Chemicals and reagents}

HPLC grade of water, orthophosphoric acid, methanol, triethylamine, and acetonitrile were purchased from Merck, Mumbai India. All pure drug substances and impurities are used for research purpose were procured in-house Macleods pharmaceutical LTD.

\section{Instrumentation}

The HPLC system consisted of Shimadzu model LC $2010 \mathrm{C}_{\mathrm{HT}}$ UV and PDA detector. The output signals were monitored and integrated using LC solution software. Sartorius analytical balance and $\mathrm{Pico}^{+} \mathrm{pH}$ meter were used.

\section{Chromatographic conditions}

The chromatographic separation was achieved on Kromasil C18 (250 x $4.6 \mathrm{~mm}, 5 \mu \mathrm{m})$ column using mobile phase consisting of buffer $\mathrm{pH} 3.2$ and acetonitrile in the ratio of $60: 40 \mathrm{v} / \mathrm{v}$. The flow rate of the mobile phase was $1.5 \mathrm{ml} / \mathrm{min}$ and isocratic program run time was $60 \mathrm{~min}$. The column temperature was maintained at $40{ }^{\circ} \mathrm{C}$ and the detection was monitored at $258 \mathrm{~nm}$. The injection volume was $30 \mu \mathrm{l}$ and acetonitrile used as diluent.

Preparation of Buffer pH 3.2: Transferred $5.5 \mathrm{ml}$ of orthophosphoric acid in $1000 \mathrm{ml}$ of water, $\mathrm{pH}$ is adjusted to 3.2 with triethylamine.

Preparation of standard and sample solutions

A stock solution of 2-cyano-4'-bromomethyl biphenyl impurity was prepared by dissolving the appropriate amount of 2-cyano-4'- 
bromomethyl biphenyl impurity in diluent. The working concentration of $0.5 \mu \mathrm{g} / \mathrm{ml}$ impurity solution was prepared from the stock solution and used as a standard solution. The sample solution (100 mg/ml) was prepared by weighing $500 \mathrm{mg}$ of drug substances and transferred to $5 \mathrm{ml}$ volumetric flask.

\section{RESULTS AND DISCUSSION}

\section{Method development}

The method was developed by considering the main parameters like the selection of wavelength, HPLC column, mobile phase, column oven temperature, flow rate, injection volume and diluent.
The solubility was checked for irbesartan, 2-cyano-4'bromomethyl biphenyl, and other impurities in water, methanol, acetonitrile and the combination of water: methanol, water: acetonitrile in different ratios. All compounds had a good solubility in acetonitrile than others diluent. Hence, Acetonitrile was selected as diluent.

The standard solution was prepared and injected into the HPLC system with PDA detector and a spectrum was obtained. The maximum absorption wavelength of the solution had shown about $258.88 \mathrm{~nm}$ (fig. 2), hence $258 \mathrm{~nm}$ was selected for the quantification of this impurity in the irbesartan drug substances.

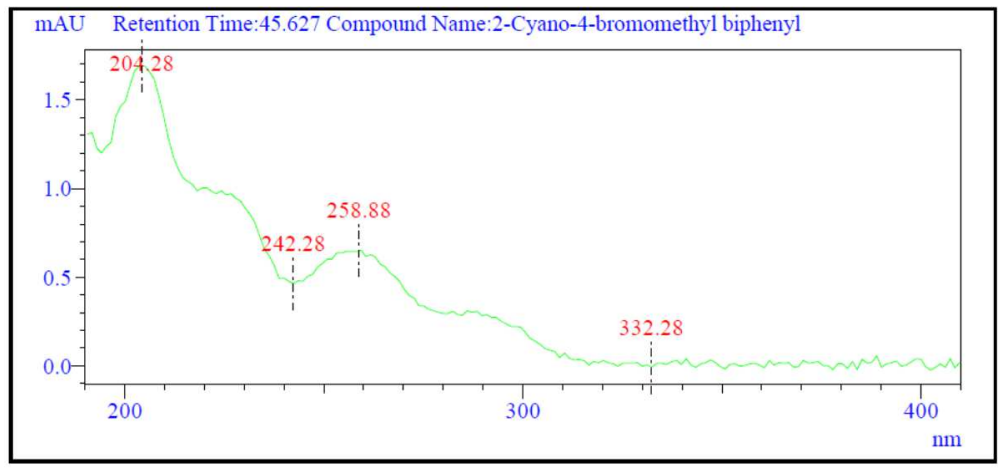

Fig. 2: Absorption spectrum of 2-cyano-4'-bromomethyl biphenyl

Main variations in the chromatographic condition tested are described in table 1 . The mobile phase consisting of buffer $\mathrm{pH} 3.2$ and acetonitrile in the ratio $60: 40 \mathrm{v} / \mathrm{v}$ provide the most adequate 2 cyano-4'-bromomethyl biphenyl satisfactory separation, clear baseline, good peak symmetry and response in the irbesartan drug substance with appropriate retention time $47.5 \mathrm{~min}$.

Table 1: Variation in chromatographic conditions, 2-cyano-4'-bromomethyl biphenyl was analyzed in HPLC equipment with UV detection fixed at $258 \mathrm{~nm}$

\begin{tabular}{|c|c|c|c|c|c|}
\hline $\begin{array}{l}\text { Mobile phase } \\
\text { (V: V) }\end{array}$ & $\begin{array}{l}\text { Flow rate } \\
(\mathrm{ml} / \mathrm{min})\end{array}$ & $\begin{array}{l}\text { Column } \\
(250 \times 4.6 \mathrm{~mm} \times 5 \mu \mathrm{m})\end{array}$ & $\begin{array}{l}\text { Injection } \\
\text { volume }(\mu \mathrm{l})\end{array}$ & $\begin{array}{l}\text { Column } \\
\text { temperature }\left({ }^{\circ} \mathrm{C}\right)\end{array}$ & Result \\
\hline Water: Methanol (50:50) & 0.5 & $\mathrm{C}_{8}$ & 5 & 25 & Peak not eluted at $60 \mathrm{~min}$ \\
\hline Water: Methanol (30:70) & 0.8 & $\mathrm{C}_{8}$ & 50 & 25 & run time \\
\hline Water: Methanol (20:80) & 1.0 & $\mathrm{C}_{18}$ & 50 & 25 & \\
\hline Water: Acetonitrile $(50: 50)$ & 1.0 & $\mathrm{C}_{8}$ & 50 & 50 & \\
\hline Water: Acetonitrile $(50: 50)$ & 2.0 & $\mathrm{C}_{18}$ & 50 & 50 & Back pressure \\
\hline Water: Acetonitrile $(60: 40)$ & 1.5 & $\mathrm{C}_{18}$ & 50 & 40 & Tailing and broad peak \\
\hline $\begin{array}{l}\text { Water: Acetonitrile: } \\
\text { Methanol }(60: 20: 20)\end{array}$ & 1.3 & $\mathrm{C}_{18}$ & 20 & 30 & Tailing and Split peak \\
\hline $\begin{array}{l}\text { Water: Acetonitrile } \\
(30: 70)\end{array}$ & 1.0 & $\mathrm{C}_{8}$ & 20 & 45 & Interference \\
\hline $\begin{array}{l}0.5 \% \text { Orthophosphoric acid: } \\
\text { Acetonitrile }(20: 80)\end{array}$ & 1.5 & $\mathrm{C}_{18}$ & 40 & 45 & Early peak \\
\hline $\begin{array}{l}0.5 \% \text { Orthophosphoric acid: } \\
\text { Acetonitrile }(20: 80)\end{array}$ & 1.2 & $\mathrm{C}_{18}$ & 40 & 25 & Interference \\
\hline $\begin{array}{l}0.5 \% \text { Orthophosphoric acid: } \\
\text { Acetonitrile }(40: 60)\end{array}$ & 1.5 & $\mathrm{C}_{18}$ & 40 & 45 & Early peak \\
\hline $\begin{array}{l}0.5 \% \text { Orthophosphoric acid: } \\
\text { Acetonitrile }(50: 40)\end{array}$ & 1.5 & $\mathrm{C}_{18}$ & 20 & 40 & Low response \\
\hline $\begin{array}{l}0.5 \% \text { Orthophosphoric acid: } \\
\text { Acetonitrile }(55: 45)\end{array}$ & 1.5 & $\mathrm{C}_{18}$ & 45 & 35 & $\begin{array}{l}\text { Tailing and no } \\
\text { reproducible }\end{array}$ \\
\hline $\begin{array}{l}0.5 \% \text { Orthophosphoric acid ( } \mathrm{pH} \\
3.2 \text { with triethylamine): } \\
\text { Acetonitrile }(60: 40)\end{array}$ & 1.5 & $\mathrm{C}_{18}$ & 30 & 40 & Suitable Peak \\
\hline
\end{tabular}

\section{Method validation}

The developed HPLC method has been validated for genotoxic impurity determination in the irbesartan sample according to ICH guideline [16]. The individual parameter of system suitability, specificity, limit of detection, limit of quantification, linearity, precision, accuracy, solution stability, and robustness was experimentally evaluated by injecting standard and sample solution.

\section{System suitability}

According to USP [17], system suitability test is an integral part of liquid chromatographic methods to verify that the system is adequate for the analysis. The standard solution was prepared and $30 \mu \mathrm{L}$ of six replicates was injected into HPLC system. The obtained peak was calculated for the \% RSD for six replicate injections of the standard was $1.39 \%<5 \%$, USP tailing factor was $1.10<2.0$ and the theoretical 
plate was 3294>2000. The result was found to comply with USP requirements and indicated that the chromatographic system is adequate for the intended analysis. Overlay chromatograms of replicate standard injection are presented in fig. 3.

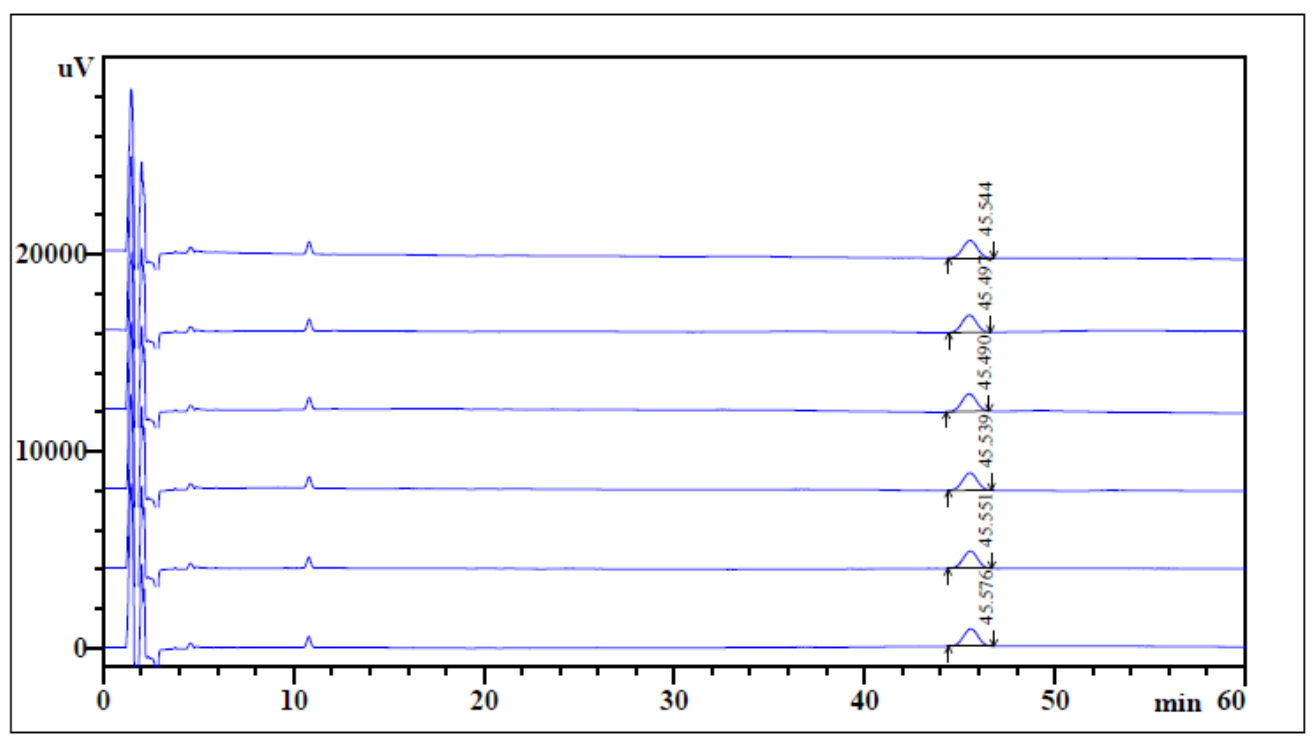

Fig. 3: Overlay chromatograms of replicate standard injections

\section{Specificity}

For demonstrating the specificity of the method blank, related compound A, 2-cyano-4'-bromomethyl biphenyl standard, irbesartan sample was prepared individually at the specification limit in the diluent and the solution of irbesartan spiked with 2cyano-4'-bromomethyl biphenyl at the evaluation limit and injected into developed chromatographic condition. The overlay chromatogram (fig. 4) indicated no chromatographic interference from any of the blank, related compound $A$, and sample peak was found at the retention time of 2-cyano-4'-bromomethyl biphenyl. These results confirm the specificity of the method without any interfering peak around the retention time of 2-cyano-4'bromomethyl biphenyl; also the baseline did not show any significant noise. The similar result reported by Prabhu and Muralidhar [10], and Rambabu et al. [15].

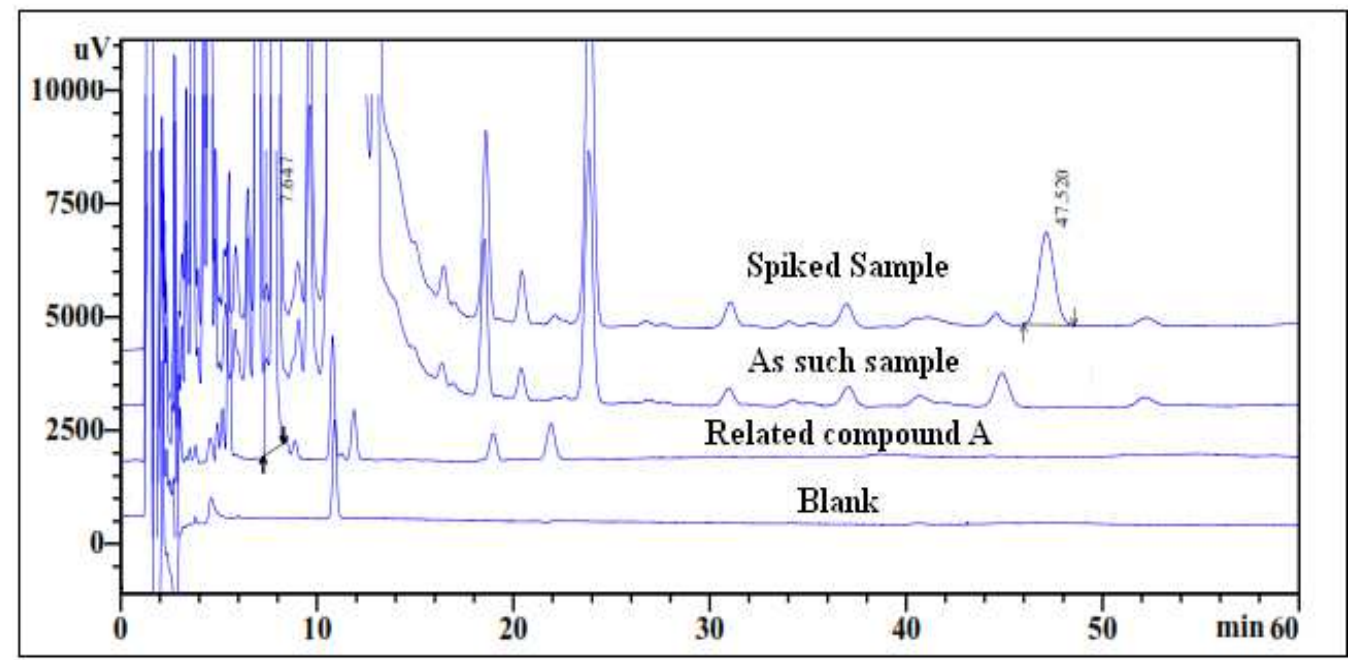

Fig. 4: Overlay chromatogram of blank, related compound A, sample and spiked sample

\section{Limit of detection and Limit of quantitation}

The LOD and LOQ for 2-cyano-4'-bromomethyl biphenyl were estimated through signal-to-noise ratio of 3:1 and 10:1 respectively, by injecting a series of dilute solutions having a known concentration $[15,16]$. LOD of the impurity is defined as the lowest concentration that can be detected. LOQ is the lowest concentration that can be quantified with acceptable precision and accuracy. The LOD was found to be $0.167 \mu \mathrm{g} / \mathrm{g}$, and LOQ was found to be 0.506 $\mu \mathrm{g} / \mathrm{g}$ (fig. 5). The low values of LOD and LOQ indicate an adequate sensitivity of the method. The percentage relative standard deviation observed for six replicates injections of LOQ solution was observed to be 1.49 , which was well within acceptance criteria, not more than $10 \%$. 


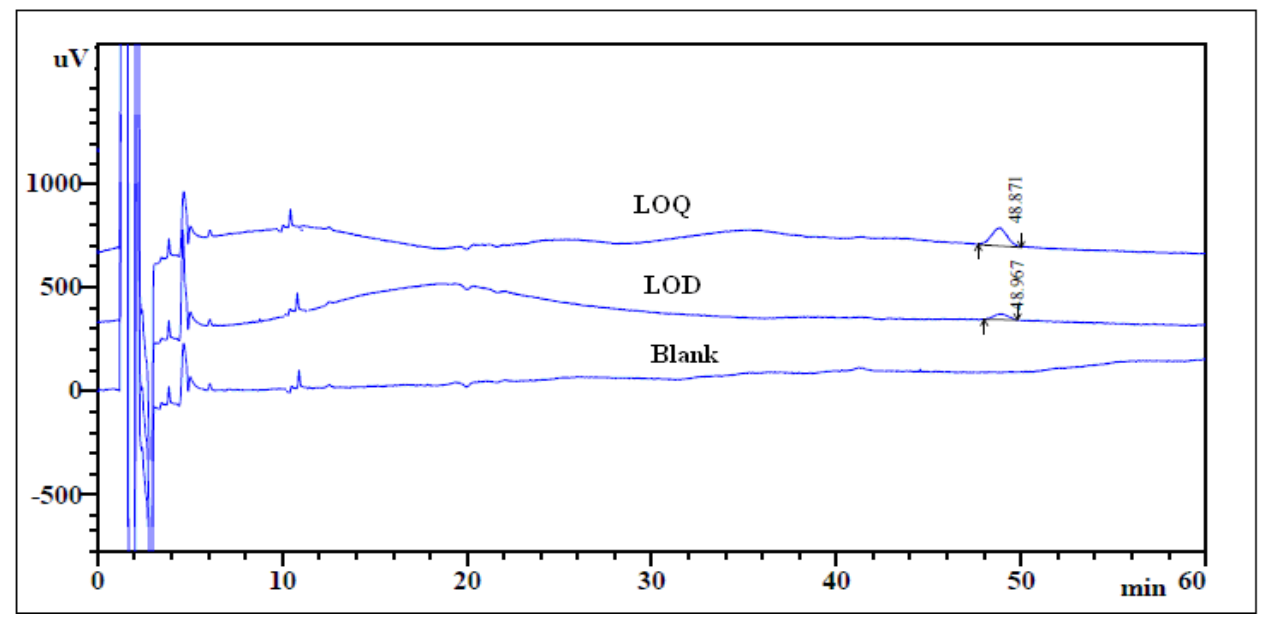

Fig. 5: Overlap chromatogram of blank, LOD and LOQ

\section{Linearity}

To establish the linearity of the developed method, calibration solution were prepared by diluting the impurity stock solution to obtain solutions at LOQ, $50 \%, 80 \%, 100 \%, 120 \%$ and $150 \%$ of the evaluation limits. Each solution was injected, and area of responses was recorded at $258 \mathrm{~nm}$. The linearity graph of peak area vs concentration in $\mu \mathrm{g} / \mathrm{g}$ was plotted (fig. 6). The correlation coefficient observed for linearity study was $0.9999>0.990$ and the best-fit linear equation obtained was $y=9880.40 x+22.65$. The result shows that an excellent correlation existed between the peak area and the concentration of the impurity over the entire concentration $[10,11]$. Overlay chromatograms of different linearity levels are presented in fig. 7.

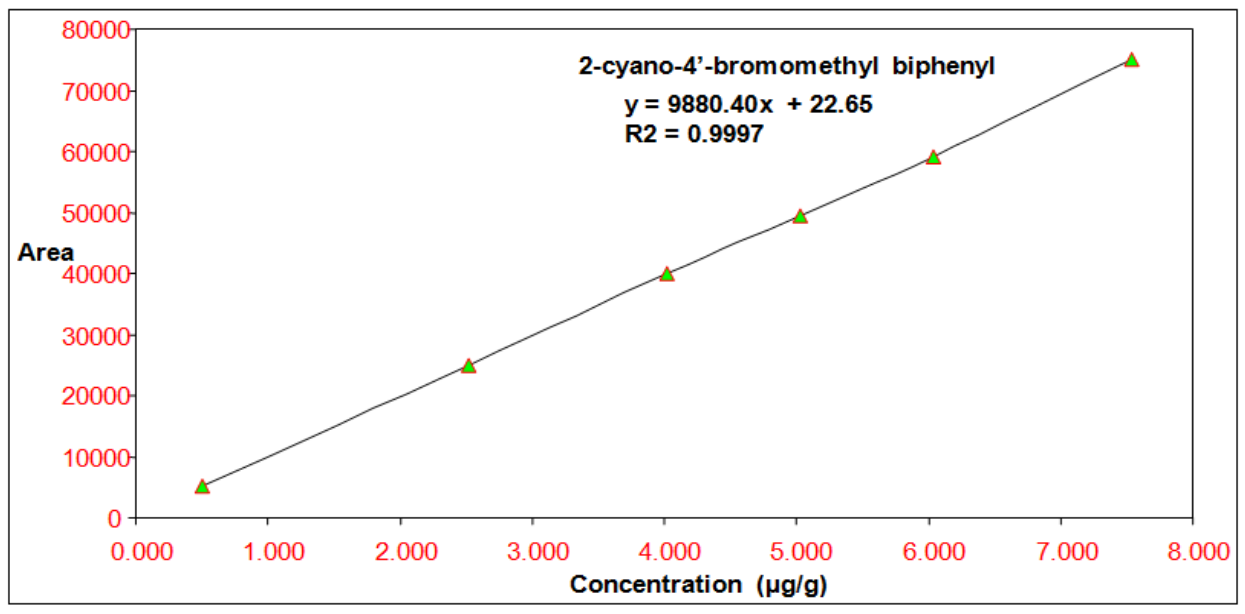

Fig. 6: Linearity of 2-cyano-4'-bromomethyl biphenyl

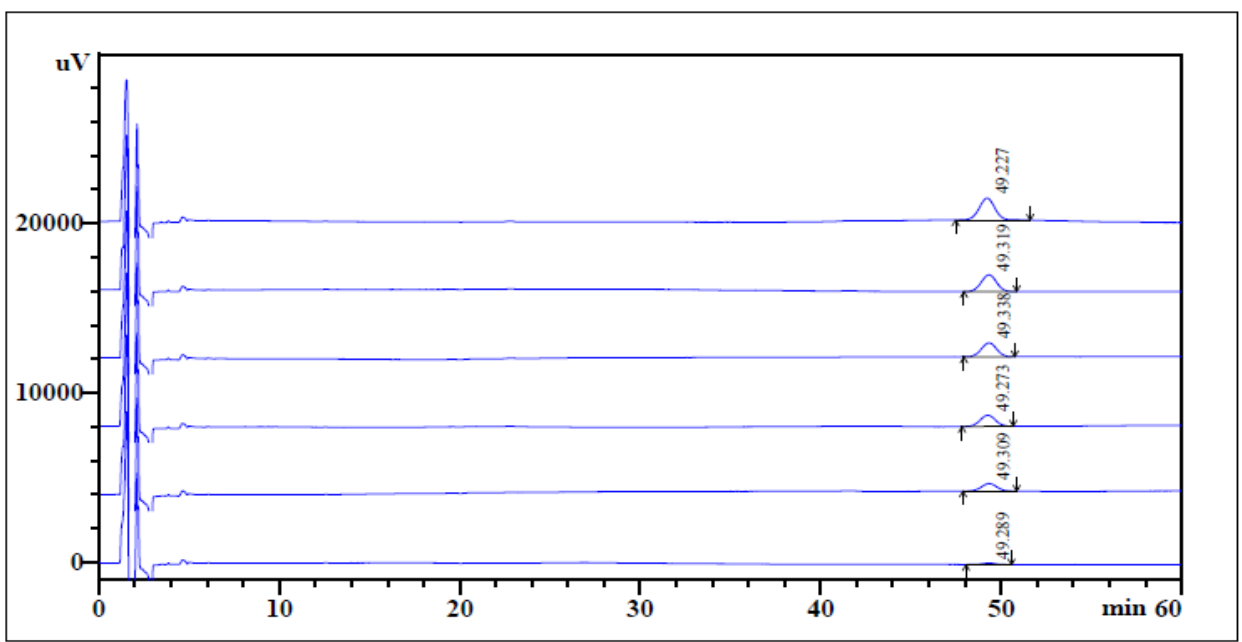

Fig. 7: Overlay chromatograms of linearity study from LOQ to $150 \%$ 


\section{Precision}

Precision was determined by repeatability and intermediate precision, Precision of the method was checked by injecting six individual preparation of irbesartan spiked with the impurity at evaluation limit. The percentage RSD of the content of impurity was calculated, and the result was found to be $1.66 \%$.

Intermediate precision of the method was evaluated by injecting six individual preparation of the spiked sample at evaluation limit on a different day in the same laboratory. The \% RSD for the content of 2cyano-4'-bromomethyl biphenyl impurity was found to be $1.17 \%$, confirmed that the high precision of the method $[14,15]$.

\section{Accuracy}

The accuracy of the method was determined by analyzing the drug substances spiked with impurity. A known amount of impurity was spiked to the irbesartan sample at different concentration levels of
LOQ, $50 \%, 100 \%$, and $150 \%$ of the evaluation limit. Each concentration level was prepared in triplicate. The percentage recovery of impurity in the drug substances was calculated. The recovery results of the 2-cyano-4'-bromomethyl biphenyl in irbesartan ranged from 98.34 to $103.46 \%$ which is well within acceptance criteria $80 \%$ to $120 \%[10,15]$. The results are summarized in table 2 and it was observed that the method was accurate within a determined range. Overlay chromatograms of accuracy are presented in fig. 8.

\section{Solution stability}

The solution stability was established by spiking 2-cyano-4'bromomethyl biphenyl impurity in irbesartan sample. The prepared solution was stored at room temperature for $24 \mathrm{~h}$. The content of impurity was determined at $4 \mathrm{~h}$ interval for $24 \mathrm{~h}$. The result was observed that no significant change in the content of the impurity [12].

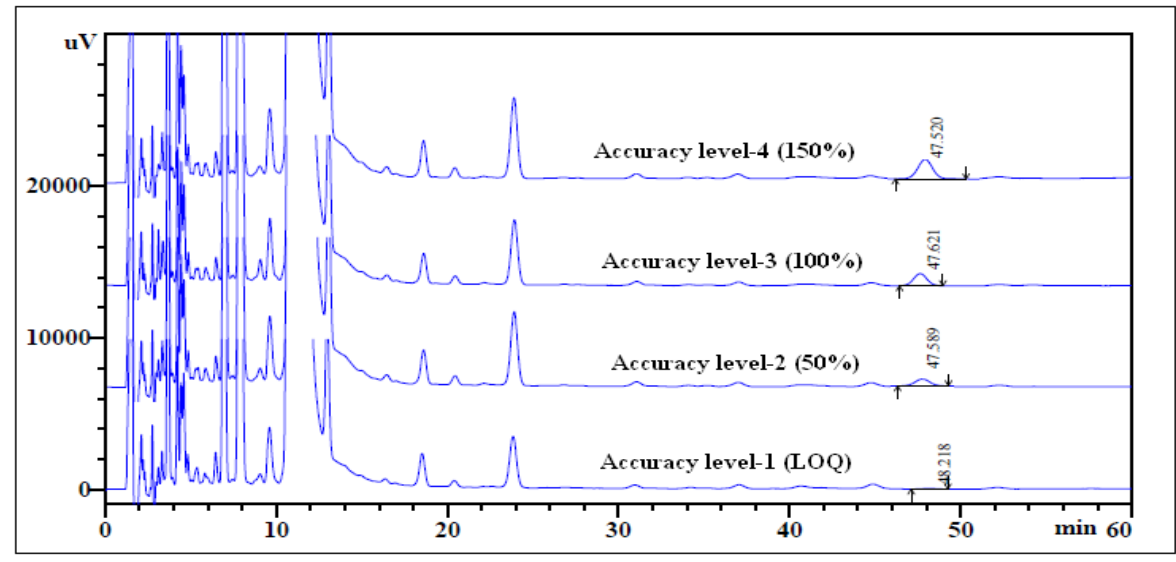

Fig. 8: Overlay chromatograms of accuracy (at LOQ, $50 \%, 100 \%$, and $150 \%$ )

Table 2: Accuracy at different spiking concentration

\begin{tabular}{|c|c|c|c|c|}
\hline Level & Amount in sample & Amount added in $(\mu \mathrm{g} / \mathrm{g})$ & Amount found in $(\mu \mathrm{g} / \mathrm{g})$ & Recovery (\%) \\
\hline \multirow[t]{3}{*}{ At LOQ } & nil & 0.551 & 0.538 & 97.64 \\
\hline & nil & 0.548 & 0.547 & 99.82 \\
\hline & nil & 0.542 & 0.533 & 98.34 \\
\hline \multirow[t]{3}{*}{$50 \%$} & nil & 2.672 & 2.649 & 99.14 \\
\hline & nil & 2.677 & 2.643 & 98.73 \\
\hline & nil & 2.671 & 2.646 & 99.06 \\
\hline \multirow[t]{3}{*}{$100 \%$} & nil & 5.326 & 5.309 & 99.68 \\
\hline & nil & 5.329 & 5.424 & 101.78 \\
\hline & nil & 5.324 & 5.508 & 103.46 \\
\hline \multirow[t]{3}{*}{$150 \%$} & nil & 7.846 & 7.779 & 99.15 \\
\hline & nil & 7.844 & 7.783 & 99.22 \\
\hline & nil & 7.842 & 7.763 & 98.99 \\
\hline
\end{tabular}

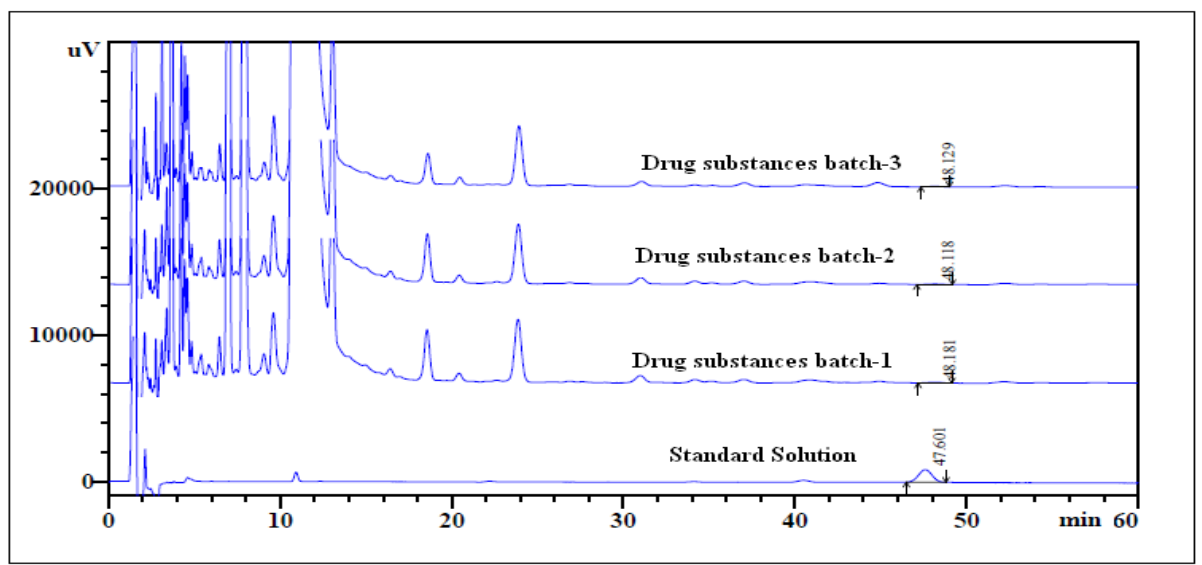

Fig. 9: Overlap chromatogram of three production batches of irbesartan sample, with standard solution 


\section{Robustness}

To determine the robustness of the method, the experimental conditions were deliberately altered and the system suitability result was evaluated. To study the effect of flow rate, it was changed by 0.1 units from $1.5 \mathrm{ml} / \mathrm{min}$ to $1.4 \mathrm{ml} / \mathrm{min}$ and $1.6 \mathrm{ml} / \mathrm{min}$. The effect of column temperature was studied by changed $5{ }^{\circ} \mathrm{C}$ units from $40{ }^{\circ} \mathrm{C}$ to $35{ }^{\circ} \mathrm{C}$ and $45{ }^{\circ} \mathrm{C}$. The results were found that the deliberate changes in the method, i.e. flow rate of mobile phase and column oven temperature has no impact on system suitability [15].

\section{Batch analysis}

The three production batches of irbesartan drug substance were analyzed in the validated method for determination of 2-cyano-4'bromomethyl biphenyl and found the impurity was below the quantitation $(0.31 \mu \mathrm{g} / \mathrm{g})$ level in all three batches. Overlay chromatograms of three production batches are presented in fig. 9.

\section{CONCLUSION}

The isocratic HPLC method developed for the trace level quantitative determination of genotoxic 2-cyano-4'-bromomethyl biphenyl in irbesartan is linear, precise, accurate, rugged and robust. Satisfactory results were obtained from validation of the method according to ICH guideline. This method exhibited an excellent performance in terms of sensitivity and specificity with no sample matrix and impurity interference observed. The sample prepared in analytical solution is found to be stable for $24 \mathrm{~h}$. This method can be used for routine analysis of the trace level quantitative determination of 2-cyano-4'-bromomethyl biphenyl in irbesartan drug substances.

\section{ACKNOWLEDGEMENT}

The authors wish to thank the management of Macleods pharmaceutical Ltd., for supporting this work.

\section{CONFLICT OF INTERESTS}

Declared none

\section{REFERENCES}

1. Virani P, Sojitra R, Raj H, Jain V. A review on irbesartan coadministered with atorvastatin for the treatment of cardiac risk. J Crit Rev 2014;1:25-8.

2. United states pharmacopoeia-39, National Formulary-34; 2016. p. 4386-90.

3. Husain A, Azim MS, Mitra M, Bhasin PS. A review of the pharmacological and pharmaceutical profile of irbesartan. Pharmacophore 2011;2:276-86.

4. Konwar M, Paul PK, Das S. Prescribing pattern of antihypertensive drugs in essential hypertension in medicine outpatients department in a tertiary care hospital. Asian J Pharm Clin Res 2014;7:142-4.

5. Panda BB, Pati MR, Sahu PK. Survey of a prescription pattern of the antihypertensive drug in hypertensive and diabetic hypertensive patients. Asian J Pharm Clin Res 2015;8:250-2.

6. Rao SN, Sitaramaiah D, Rao CN, Rao PS, Babu KS. Commercial scalable process for the preparation of irbesartan intermediate. Rasayan J Chem 2010;3:681-9.

7. Zupancic S, Bevk D, Zupet R. A new process for the preparation of irbesartan. EP 2194050A1; 2010.

8. International conference on harmonization, Assessment, and control of DNA reactive (Mutagenic) impurities in pharmaceuticals to limit potential carcinogenic risk M7; 2014.

9. European medicines agency evaluation of medicines for human use, guideline on the limits of genotoxic impurities; 2006.

10. Prabhu P, Muralidhar M. Development and validation of a high-performance liquid chromatography method for simultaneous determination of irbesartan and its related impurities in pharmaceutical tablets. Int J Pharm Sci Drug Res 2014;6:145-53.

11. Kalyankar TM, Wadher SJ, Pekamwar SS, Doiphode NG. Development and validation of RP-HPLC method for estimation of hydrochlorothiazide and irbesartan in a pharmaceutical preparation. Int J PharmTech Res 2014;6:330-6.

12. Swamy GK, Kumar JMR, Rao JVLNS. A validated reverse phase HPLC method for the simultaneous estimation of irbesartan and amlodipine in pharmaceutical dosage form. W J Pharm Pharmacol Sci 2014;3:996-1007.

13. Virani P, Sojitra R, Raj H, Jain V. Chromatographic method for irbesartan and its combination with another drug. J Crit Rev 2015;2:7-11.

14. Reddy AV, Venugopal N, Madhavi G, Madhavi V, Reddy KG. A systematic approach for trace level quantification of 2-N-butyl4-spirocyclopentane-2-imidazole-5-one genotoxic impurity in irbesartan using LC-MS/MS. Indian J Pharm Sci 2013;75:501-6.

15. Rambabu D, Prasad PSS, Mukkanti K. A novel sensitive and rapid method developed for simultaneous quantification of two potential genotoxic impurities in irbesartan by UPLC. J Pharm Res 2012;5:5401-3.

16. International conference on harmonization; Validation of analytical procedures: Text and methodology Q2; 2005.

17. United States Pharmacopoeia. General chapter $<621>$ “Chromatography”, USP 37, NF; 2014. p. 32.

\section{How to cite this article}

- S Senthil Kumar, Ritesh Kumar Srivastava, V Srinivas rao. Determination of 2-cyano-4'-bromomethyl biphenyl Genotoxic impurity in irbesartan drug substances using HPLC technique. Int J Pharm Pharm Sci 2016;8(12):225-230. 